of anthropology, economics, history, linguistics, literature, music, philosophy, religion, sociology, etc. With this wealth of knowledge and experience available, it is hoped that, with a spirit of cooperation, individuals will be able to gain new insight and appreciation for this vast geographical area.

To communicate the activities of the Society and other lectures or conferences of other learned societies, a Newsletter will be printed three times a year. The bulletin, Scripta Mediterranea, will be published annually and will include scholarly articles, bibliographies, book reviews and brief communications. For further information or to submit manuscripts, write to: J.K. Hoffmeier, Centre for Religious Studies, University of Toronto, Robarts Library (14335), Toronto, Ontario, Canada M5S-1A1.

Fees: A nominal membership fee will be assessed annually to meet the Society's expenses. The level of dues will be approved by a majority vote during the annual general meeting. Fees from April 1, 1980 to March 31, 1981 are: $\$ 5.00$ - Students; $\$ 10.00$ - Other Members. Fees include subscriptions to Newsletter and Bulletin. For membership information, contact: D.A. Agius, Society for Mediterranean Studies, University of Toronto, Robarts Library (14087), Toronto, Ontario, Canada M5S-1A1.

\title{
Southeast Regional Extended Teacher Institute
}

Old Dominion University in Norfolk, VA and Emory University in Atlanta, GA will conduct Extended Teacher Institutes in Middle East Studies in 1981-1982 and 1982-1983, supported by a \$354,261 grant from the National Endowment for the Humanities (\$254,261 outright grant and $\$ 50,000$ matching challenge grant). The project, which is co-directed by Dr. Jerome B. Weiner of Old Dominion and Dr. Kenneth W. Stein of Emory, was conceived and planned by members of the Southeast Regional Middle East and Islamic Studies Seminar (SERMEISS). It also involves officials from the state education departments of Alabama, Georgia, Kentucky, North Carolina, South Carolina, Tennessee, Virginia and West Virginia. It will be the largest such project ever undertaken in Middle East studies.

The purpose of the project is to begin a process of improving instruction about the Middle East in secondary schools in the Southeast by training 150 teachers in Middle East studies and helping them design curriculum units for use in their classes. This will be accomplished at five-week summer institutes at Old Dominion in June-July, 1981 and at Emory in June-July, 1982. In addition, there will be extensive follow-up activities during the school year following each summer program.

For further information about this Teacher Institute, contact either: Dr. Jerome B. Weiner, Old Dominion University, Norfolk, VA 23508; or Dr. Kenneth W. Stein, Emory University, Atlanta, GA 30322.

\section{RECENT CONFERENCES}

$\frac{\text { Religion and Politics in the Islamic Middle East }}{\text { Ohio State University, Columbus - April 24-25 }}$

Soheyl Amini-Ohio State U: The Contribution of Ali Shariati to the Formation of Revolutionary Ideology in Islamic Iran-An Overview. Marcella Bedford-Ohio State U: The Iconography of Romantic Paintings by the Pakistani Artist, Abdur Rahman Chughtai.

David C. Gordon-Wright State U: Islam and Algeria's Self-Definition. 